\title{
ARTICLE OPEN Wearable multifunctional printed graphene sensors
}

\author{
Altynay Kaidarova (D) ${ }^{1}$, Mohammed Asadullah Khan ${ }^{1}$, Marco Marengo ${ }^{1}$, Liam Swanepoel ${ }^{1}$, Alexander Przybysz ${ }^{1}$, Cobus Muller $^{2}$, \\ Andreas Fahlman ${ }^{3}$, Ulrich Buttner ${ }^{1}$, Nathan R. Geraldi $\mathbb{D}^{4}$, Rory P. Wilson ${ }^{5}$, Carlos M. Duarte (iD ${ }^{4}$ and Jurgen Kosel (iD ${ }^{1}$
}

The outstanding properties of graphene have initiated myriads of research and development; yet, its economic impact is hampered by the difficulties encountered in production and practical application. Recently discovered laser-induced graphene is generated by a simple printing process on flexible and lightweight polyimide films. Exploiting the electrical features and mechanical pliability of LIG on polyimide, we developed wearable resistive bending sensors that pave the way for many cost-effective measurement systems. The versatile sensors we describe can be utilized in a wide range of configurations, including measurement of force, deflection, and curvature. The deflection induced by different forces and speeds is effectively sensed through a resistance measurement, exploiting the piezoresistance of the printed graphene electrodes. The LIG sensors possess an outstanding range for strain measurements reaching $>10 \%$ A double-sided electrode concept was developed by printing the same electrodes on both sides of the film and employing difference measurements. This provided a large bidirectional bending response combined with temperature compensation. Versatility in geometry and a simple fabrication process enable the detection of a wide range of flow speeds, forces, and deflections. The sensor response can be easily tuned by geometrical parameters of the bending sensors and the LIG electrodes. As a wearable device, LIG bending sensors were used for tracking body movements. For underwater operation, PDMS-coated LIG bending sensors were integrated with ultra-low power aquatic tags and utilized in underwater animal speed monitoring applications, and a recording of the surface current velocity on a coral reef in the Red Sea.

npj Flexible Electronics (2019)3:15; https://doi.org/10.1038/s41528-019-0061-5

\section{INTRODUCTION}

Bending sensors provide an electrical signal as a function of the bending radius or curvature. ${ }^{1}$ Such sensors offer an extremely versatile sensing platform capable of measuring changes of various physical quantities. They can be made lightweight, lowcost, and robust and tolerate vibration, thermal shock and stretching without electromagnetic interference or sensor occlusion. $^{2}$ The application areas of bending sensors are rapidly increasing, including medical, ${ }^{3,4}$ automotive, ${ }^{5}$ industrial, ${ }^{6,7}$ physical activity measurements, ${ }^{6,8}$ and human-machine interactions. ${ }^{9}$ In case of passive resistive bending sensors, an electrically conductive pattern or electrode is fabricated on top of a flexible substrate, and changes its resistance upon substrate bending. These electrodes have been realized by on carbon-based materials (powder, ${ }^{10}$ ink, ${ }^{11}$ and particles ${ }^{12}$ ), transition metals (silver, ${ }^{13}$ copper $^{14}$ and platinum ${ }^{15}$ ), and conductive polymers, ${ }^{16}$ which determine the basic electrical properties of the sensor.

In this paper, we exploit the piezoresistance of graphene electrodes printed on flexible polyimide (PI) films. Graphene has been extensively exploited recently as an alternative to traditional materials, due to its superior properties, such as high conductivity, flexibility, transparency, and biocompatibility, ${ }^{17,18}$ There is a number of reports investigating electromechanical properties of the graphene based on CVD, ${ }^{19-21}$ mechanically exfoliated graphene, ${ }^{22,23}$ graphene oxide, ${ }^{24-26}$ and hydrogenated graphene oxide. $^{20,27}$ The intrinsic piezoresistivity of single-layer graphene is rather limited as the hexagonal mesh of graphene can withstand strains only below $\sim 0.7 \%$ with gauge factors (GF) of $\sim 1.4-2 .^{28-31}$ Meanwhile, the responsivity of multilayered structures, such as graphene oxide ${ }^{24-26}$ and hydrogenated graphene oxide is significantly higher. $^{20,27}$ The high variation of the electrical resistance of multilayer samples under strain was explained by the displacement of the layers and changing their overlapping area, which provides the ability to use these structures for force and strain sensors. ${ }^{20}$

In 2014, it was discovered that direct lasing of PI films leads to the formation of $3 \mathrm{D}$ porous graphene, ${ }^{32-34}$ by a photothermal process associated with a localized high temperature, the pressure produced by laser irradiation and easy absorption of longwavelength radiation. This process enables the development of LIG bending sensors that are mechanically flexible, lightweight, robust, and multifunctional. Several studies on LIG strain sensors have investigated the laser power effect on the GF of the functionalized LIG, ${ }^{35-37}$ some focused on embedding LIG on cured elastomers, ${ }^{38-41}$ while others discovered alternative lasers that fabricate LIG, ${ }^{42,43}$ The piezoresistive properties of LIG were utilized for generating and detecting sounds, ${ }^{43}$ gesture registration, ${ }^{35}$ respiratory rate, ${ }^{44}$ and human-machine interface. ${ }^{40}$ The LIG sensors in this study are used for the detection of curvature, force, deflection, and flow. The LIG bending sensor can also operate in harsh conditions, and is fabricated by a simple process without the requirement for a clean room, solvents, and subsequent treatments or other supporting processes. The sensor is customized for different applications simply by adopting the

\footnotetext{
${ }^{1}$ Computer, Electrical and Mathematical Sciences \& Engineering (CEMSE) King Abdullah University of Science and Technology(KAUST), Thuwal 23955, Saudi Arabia; ${ }^{2}$ Mechanical

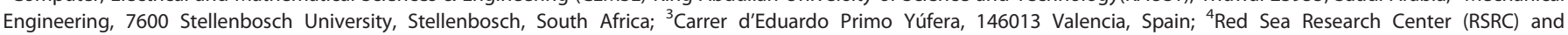

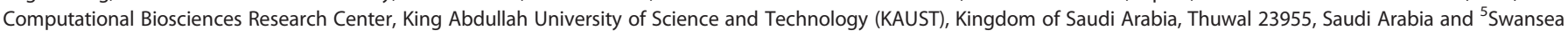
Lab for Animal Movement, Biosciences, Swansea University, Swansea SA2 8PP Wales, UK

Correspondence: Jurgen Kosel (jurgen.kosel@kaust.edu.sa)
}

Received: 27 February 2019 Accepted: 15 July 2019

Published online: 02 August 2019 
geometry, while achieving a homogeneous bidirectional response, temperature compensation, and high accuracy.

Here, we demonstrate the versatility and potential of LIG sensors, and challenge their performance under harsh conditions. In particular, we used LIG sensors as a wearable device to monitor body movements of marine animals in various locations in the Red Sea. We did so by combining the LIG sensors with ultra-low power aquatic tags. The Red Sea is the warmest (up to $36^{\circ} \mathrm{C}$ in surface waters $)^{45}$ and saltiest ( $20 \%$ above standard ocean salinity ${ }^{46}$ ) of all seas, and offer conditions prone to corrosion and pressure-derived failure of electronic devices.

Speed sensing of underwater animals is especially challenging, due to the harsh conditions in the Red Sea combined with the requirement for low weight, size, and power consumption. Speed sensing of marine animals is fundamental to quantify their energy expenditure, which, in turn, is crucial for understanding their foraging behaviors, biogeography, life history, and many conservation efforts. ${ }^{47}$ Animal-attached bending sensors could provide an opportunity to observe energy expenditure by quantifying the velocity of the animal body over time. ${ }^{48}$ The most commonly employed method for speed sensing is the overall dynamic body acceleration, where a derivative of acceleration is used as a proxy for the metabolic rate. ${ }^{48}$ This indirect method suffers from the inability to estimate the energy budget in the case of stationary activities and time-varying flow velocity. Other methods have exploited turbines, ${ }^{49,50}$ paddle wheels ${ }^{51}$ rotated by ambient water flow, and reflectance of infrared light against a flexible paddle. ${ }^{52}$ Meanwhile, commercially available flow sensors use various operating principles, such as differential pressure meters, ${ }^{53}$ variable area flowmeter, ${ }^{54}$ electromagnetic, ${ }^{55}$ vortex $^{56}$ ultrasonic, $^{57}$ and Coriolis mass. ${ }^{58}$ These solutions have limited capabilities, either due to fragile moving part or high installation and maintenance cost. They are also susceptible to biofouling and blockage due to an accumulation of foreign particles. Additional protective housings, employed to remedy some of these issues, increase the size, buoyancy and weight associated with the device, which has been shown to influence animal behavior, swimming, and diving performance. ${ }^{7}$ Another active research area is oriented toward obtaining spatiotemporal information of human body movements using flexible, noninvasive, cost-effective, lightweight, and low-power sensors to continuously track segments of the body over extended periods and without reducing freedom of movement. LIG bending sensors could be advantageously utilized for longterm monitoring of human movement in kinesiology, physiotherapy, rehabilitation, telehealth, or in the control of prosthetic limbs.

\section{RESULTS AND DISCUSSION}

Characterization of LIG bending sensor

The surface morphology of the carbon network patterns was qualitatively investigated by scanning electron microscopy (SEM, Quanta 600FEG Systems). A cross-sectional view of the carbon patterns on top of the PI film is shown in Fig. 1, indicating that the entire volume of the LIG is comprised highly porous nanomaterials. The structural characteristics of the porous graphene were also examined via confocal Raman spectrum (Fig. 1d), revealing three distinctive peaks at $1360 \mathrm{~cm}^{-1}$ (D-band), $1580 \mathrm{~cm}^{-1}$ (Gband), and $2720 \mathrm{~cm}^{-1}$ (2D-band) and thereby, suggesting the presence of graphene sheets in the porous structure. The $\mathrm{G}$ peak is related to the vibration of sp2 carbon atoms in the hexagonal plane, and its intensity is lower in monolayer graphene. ${ }^{59}$ The $D$ peak is activated by disorder and defects and correspond to intravalley double resonance processes. ${ }^{60}$ The $2 \mathrm{D}$ peak is the key one in monolayer graphene that reduces and widens, as the number of layers increases. ${ }^{61}$ The XPS spectrum, shown in Fig. 1e, reveals a dominant $\mathrm{C}-\mathrm{C}$ peak, with greatly suppressed $\mathrm{C}-\mathrm{O}, \mathrm{C}=$ $\mathrm{O}$, and $\mathrm{COO}$ peaks, suggesting the dominance of $\mathrm{sp}^{2}$-carbon in LIG. $^{47}$
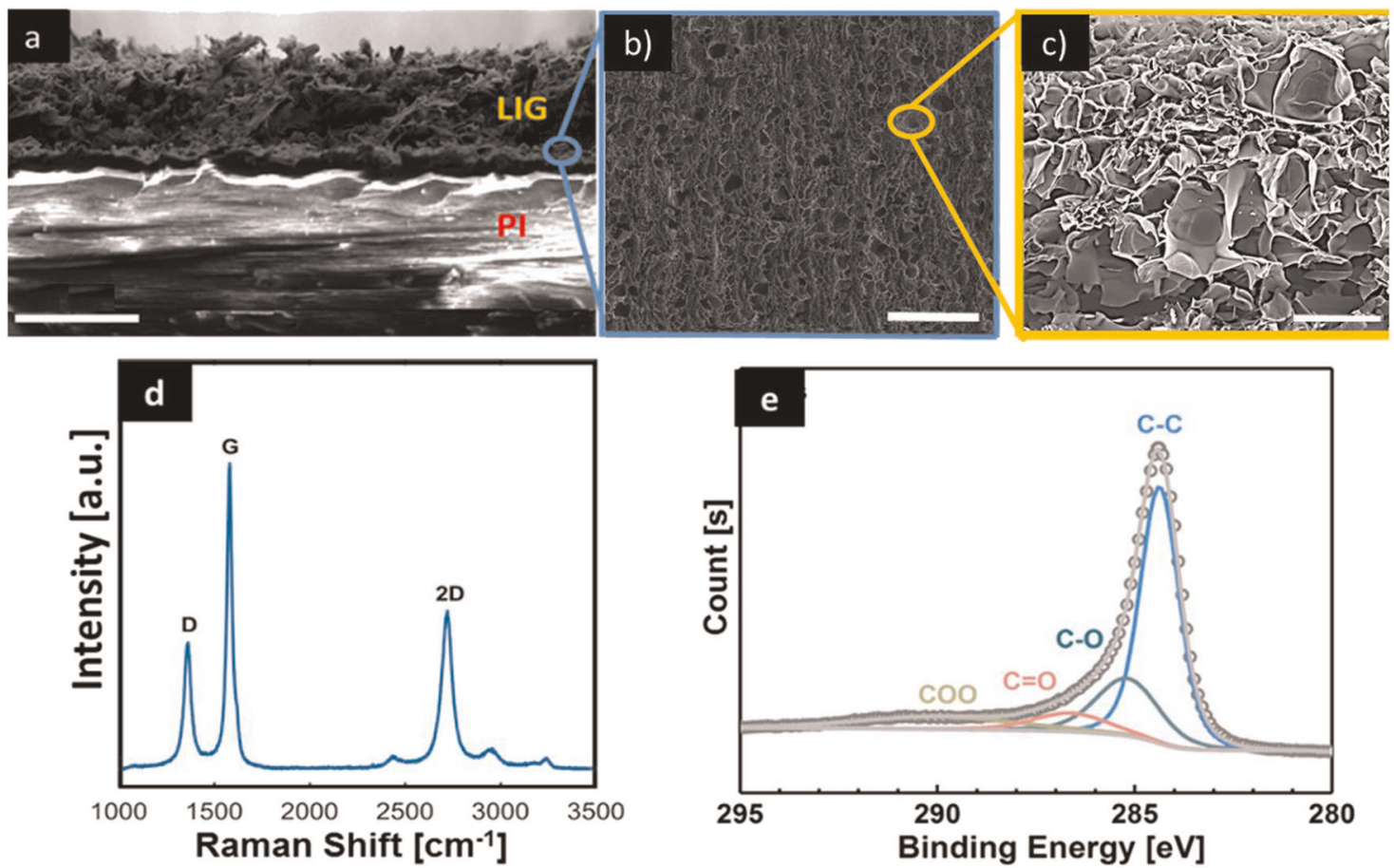

Fig. 1 a Cross-sectional SEM image of the porous carbon network lying on the top of polyimide (scale bar: $30 \mu \mathrm{m}$ ). $\mathbf{b}$ Low-magnification SEM image shows the porous morphology of LIG (scale bar: $15 \mu \mathrm{m}$ ). c High-magnification SEM image shows the graphene flakes randomly arranged and interconnected (scale bar: $5 \mu \mathrm{m}$ ). d Raman spectrum of LIG acquired with a laser wavelength of $473 \mathrm{~nm}$. e High-resolution XPS spectrum of the C1s region of LIG 
A typical factor used to characterize strain sensors is the Gauge factor (GF),

$$
\mathrm{GF}=\frac{\mathrm{d} R / R}{\mathrm{~d} l / I}=\frac{\mathrm{d} \rho / \rho}{\varepsilon}+1+2 \nu,
$$

where $\Delta \mathrm{l} / \mathrm{I}$ is the strain, $R$ is the resistance under zero strain, $\rho$ is the electrical resistivity, $v$ is the Poisson ratio $\left(v_{\text {Kapton }}=0.34\right) .{ }^{62} \mathrm{An}$ LIG electrode in the form of a strip with a length of $30 \mathrm{~mm}$, a width of $2 \mathrm{~mm}$, and initial resistance of $\sim 0.7 \mathrm{k} \Omega$ was used to evaluate the GF. Both ends of the strip were fixed by sample holders (inset of Fig. 2) of an electromechanical pull tester (5900-Series, Instron Inc.), which provided a continuously increasing force and measurement of the resulting displacement. A continuous current of $1 \mathrm{~mA}$ was applied through the graphene strain sensor (as in all consecutive experiments) to measure the change of electrical resistance during the tensile deformation of the sensor with a Keithley 2400 Source Meter. Figure 2 reveals a linear relationship between strain and relative change in resistance. The increase in resistance is attributed to a narrow and long conductive porous structure. The $\mathrm{GF} \simeq 11.2$ (Young modulus $\simeq 2.1 \mathrm{GPa}$, yield strength $\simeq 83 \mathrm{MPa}$ ) is extracted from the slope, and is in the range of the values of metal strain gauges. Note, the maximum strain applied was $>10 \%$. The intrinsic contribution to the piezoresistivity was

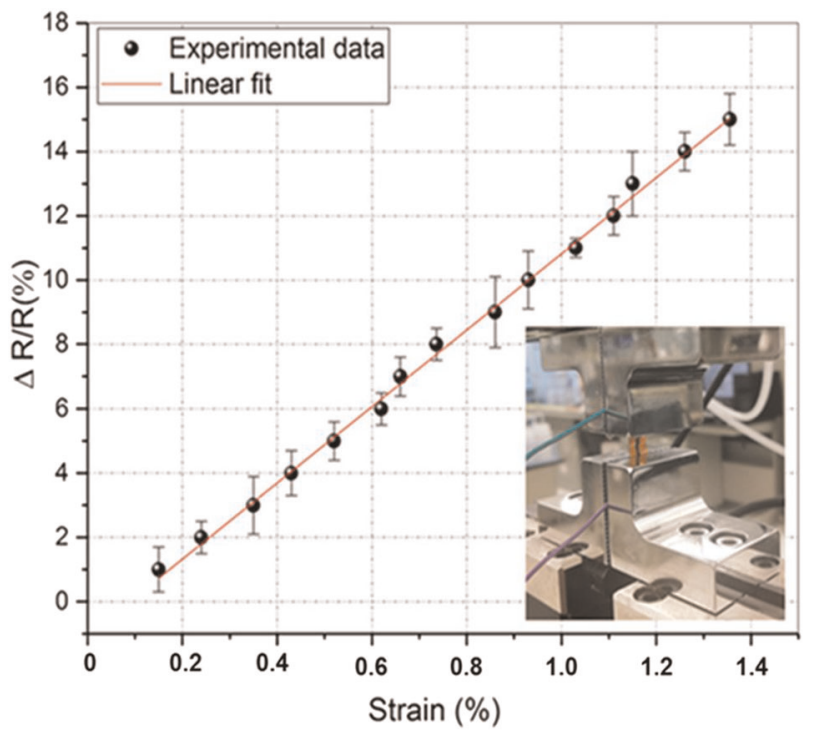

Fig. 2 Strain-induced resistance change of LIG

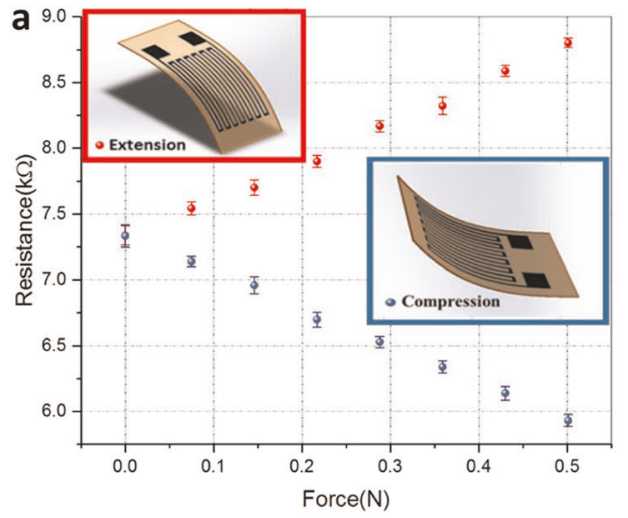

found to have $((d \rho / \rho) / d l / I=0.84)$ a positive sign, suggesting a positive piezoresistivity.

Force, deflection, and flow detection

The electromechanical pull tester was used to induce deflection of the LIG sensor, as shown in the insets of Fig. 3. The resistance variation of the sensor in tension state (LIG on the convex side) has a linear relationship with the exerted force and the sensor deflection. The electrical resistance of the LIG sensor, shown in Fig. $3 a$ (width: $7 \mathrm{~mm}$, length: $7.6 \mathrm{~mm}$, number of turns: 11), increases at the rate of $\sim 2.98 \Omega / \mathrm{mN}$ and $\sim 0.21 \Omega / \mu \mathrm{m}$ at room temperature. Conversely, the LIG bending sensor shows a decreasing resistance in compression state (LIG on the concave side), reducing at the rate of $\sim 2.91 \Omega / \mathrm{mN}, \sim-0.21 \Omega / \mu \mathrm{m}$ (Fig. 3). The absolute change in resistance is tailored by the number of turns of the LIG electrodes as seen in Fig. S1a. An increased number of turns with the same dimensions did not affect the normalized sensitivity, since the percentage change in resistance for a given strain for the entire LIG path is the same as for any single trace. Using shorter electrodes $(7 \mathrm{~mm})$ results in a higher sensitivity than longer ones $(15 \mathrm{~mm})$ with the same number of turns (Fig. S1b), as expected from Eq. (3).

To test the response of a LIG bending sensor to different flow rates, a setup was constructed wherein a fluid flowing inside a tube bent the sensor toward the direction of fluid flow (Fig. 4). The bulk flow of the fluid is quantized by the bending moment exerted on the bend sensor that is caused by the drag associated with the flowing fluid. ${ }^{5}$ The flow tube for sensor testing was assembled using two segments of opaque PVC (0.73-m length)

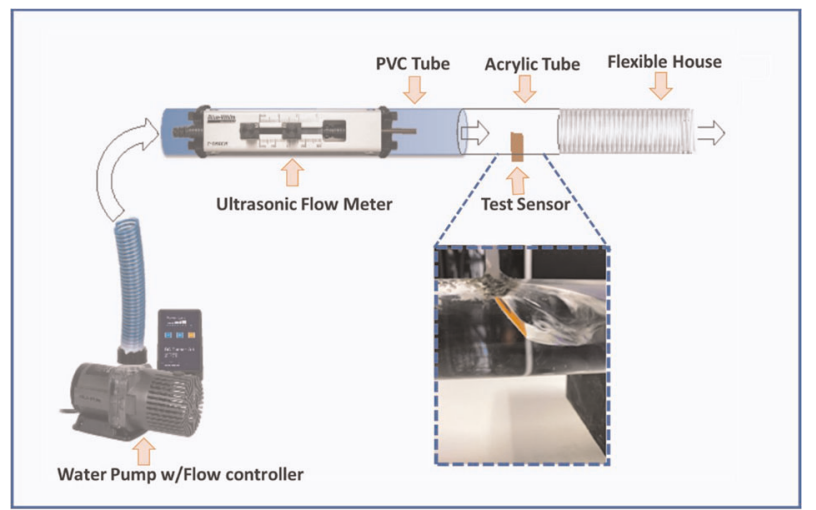

Fig. 4 Schematic of the flow test setup. The inset shows the bending the LIG sensor toward the direction of fluid flow

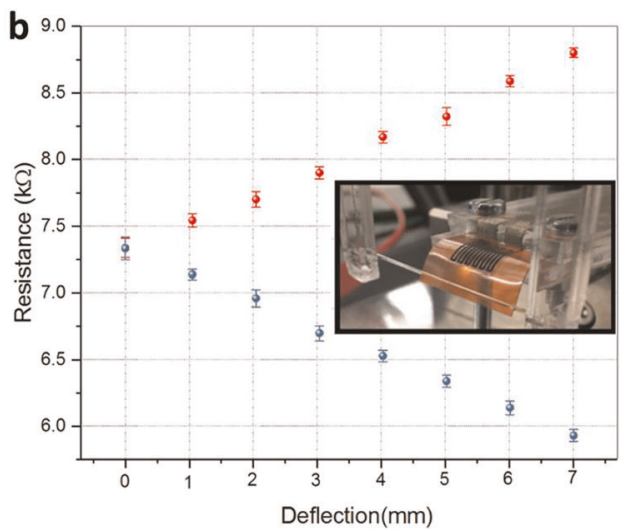

Fig. 3 Average resistance as a function of $\mathbf{a}$ force and $\mathbf{b}$ deflection induced during extension and compression of LIG. The error bars indicate the standard deviation. The coefficient of determination $\left(R^{2}\right)$ is 0.9961 during extension and 0.9984 during compression 

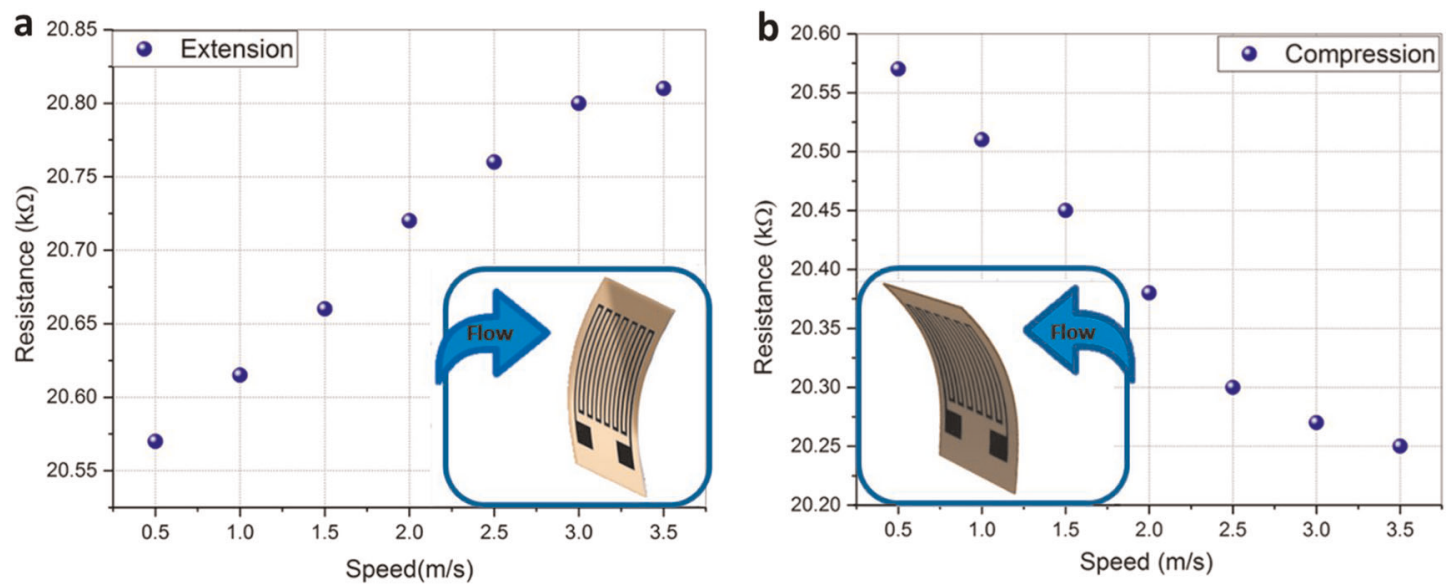

Fig. 5 The response of the bending sensor to different flow velocities, when the LIG electrode is a extended and $\mathbf{b}$ compressed
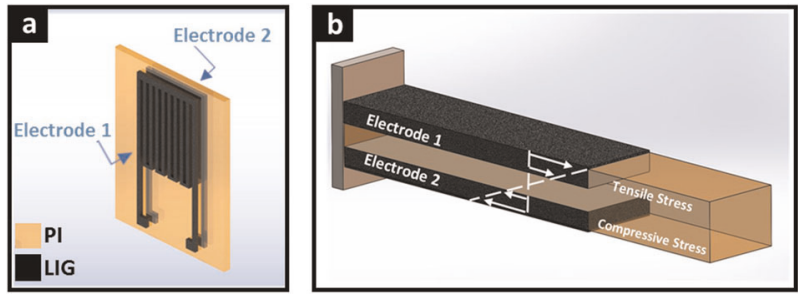

Fig. 6 Schematics of $\mathbf{a}$ a double-sided LIG bending sensor and $\mathbf{b}$ its cross-section with the stress, due to bending

and transparent acrylic $(0.29 \mathrm{~m})$, with the same internal diameter of $36 \mathrm{~mm}$. A ball valve, for the regulation of the flow rates during testing, was fitted to one end of the PVC pipe, which was connected by a flexible hose to a submerged pump (DC Runner 2.1, Aqua Medic) in a seawater basin. The ultrasonic flow meter (Siemens Sitrans, FUP 1010) was installed on the PVC section of the flow tube for measuring the water flow rates to the test sensor that was vertically fixed and adhesive-sealed through a slit on the acrylic tube. With the acrylic tube being transparent, it provided clear visualization of the sensor bending at various flow rates during testing. Hence, the flow experiments were conducted with a velocity up to $3 \mathrm{~m} / \mathrm{s}$ to minimize effects of turbulent flows. Figure $5 \mathrm{a}$ and $\mathrm{b}$ show responses of the bending sensor, when the water flow induces tension and compression, respectively, in the LIG electrodes. The sensor response is linear within the speed range of $0.5-3 \mathrm{~m} / \mathrm{s}$. The sensitivities obtained for the flow sensor are $\sim 100 \Omega /(\mathrm{m} / \mathrm{s})$ and $\sim 110 \Omega /(\mathrm{m} / \mathrm{s})$, for the cases of LIG tension and compression, respectively.

\section{Double-sided LIG sensor}

The sensor concept in combination with the simple fabrication process, allow fabricating a double-sided LIG sensor, where the LIG electrodes are patterned on both sides of the PI film (Fig. 6a, b). By utilizing a difference measurement, where the output signals of the sensor under compression and tension are subtracted, several advantages arise. First, an equal directional response is obtained for both bending directions, since compressive and tensile responses are added up. Second, the output voltage is zero under zero-load condition, allowing for higher signal amplification. Third, a rejection of common input signals is achieved. An example for the latter is the effect of temperature, which is removed by using the double-sided LIG sensor. As previously reported, the resistance of LIG electrodes decreases by $4 \%$ over a temperature range of $20-60{ }^{\circ} \mathrm{C} .{ }^{63}$ By measuring the resistance change of both sensor electrodes of the LIG sensor (Fig. 7a) and subtracting them from each other (Fig. 7b), the electrode deflection and applied force can be determined, with the same sensitivity in both bending directions. Since both LIG electrodes are affected by the same temperature (Fig. 8a), signal subtraction results in a complete compensation of the temperature effect (Fig. 8b). This is possible, due to the close proximity of the printed electrodes $(\sim 50 \mu \mathrm{m})$ and high thermal conductivity of PI $(0.46 \mathrm{~W}$ $\left.\mathrm{m}^{-1} \mathrm{~K}^{-1}\right)$.

\section{Marine animals monitoring}

The LIG bending sensors proves a powerful tool, when coupled with aquatic tags, such as Aquamote ${ }^{64}$ and Daily diary, ${ }^{65}$ to allow reconstruction of fine-scale behavior. Animal monitoring experiments were carried out at the Oceanographic Foundation Research Center in Valencia on a Bottlenose dolphin (the genus Tursiops) and a Loggerhead sea turtle (Caretta caretta). To this end, an LIG sensor of $17.2 \mathrm{k} \Omega$ resistance, shown in Fig. 9 (width: $7 \mathrm{~mm}$, length: $15 \mathrm{~mm}$, number of turns: 11), was integrated with a commercial tag (ICM-20948, TDK InvenSense), which was attached to the dolphin's spine noninvasively by a vacuum sucker (Fig. 10a), and the turtle's carapace by a waterproof velcro (VLC02, Velcro ${ }^{\circledR}$ Brand Marine Grade Hook and Loop) and pure epoxy compound (Subcoat S, Veneziani Yachting) (Fig. 11a). The resistance of the LIG tag was recorded during a dolphin's training session and translated to swimming speeds via a calibration obtained from Fig. 6. Different maneuvers, such as shallow-, medium-, and deep diving and swimming (Fig. 10b) were carried out by the dolphin in $3 \mathrm{~min}$, and were clearly reflected in the sensor response, with a maximum speed of $\sim 2.7 \mathrm{~m} / \mathrm{s}$ reached during deep diving and an average speed of $\sim 0.8 \mathrm{~m} / \mathrm{s}, \sim 1.3 \mathrm{~m} / \mathrm{s}, \sim 2 \mathrm{~m} / \mathrm{s}$, and $\sim 0.4 \mathrm{~m} / \mathrm{s}$ for shallow-, medium-, and deep diving and swimming, respectively. The overall average and median speeds of the Bottlenose dolphin were $\sim 0.32 \mathrm{~m} / \mathrm{s}$ and $\sim 0.3 \mathrm{~m} / \mathrm{s}$, respectively. The speed recorded when the dolphin was swimming at the surface of the water is likely inaccurate, due to submerging of the sensor. A different sensor position could help remedying this problem.

The measurements of the sea turtle's speed required a more sensitive speed sensor than the one used for the dolphin, due to the slower motion of the turtle. As described above, the sensitivity can be easily tailored by increasing the cantilever length or area. Therefore, the sensor design was modified to increase its area by the addition of a $2 \times 2 \mathrm{~cm}^{2}$ patch, as shown in Fig. S3. The sea turtle reached the maximum speed of $\sim 1.82 \mathrm{~m} / \mathrm{s}$, when swimming to the surface to breath, which happened seven times during the recorded $\sim 4 \mathrm{~h}$ (Fig. 11b). The average and median speeds of the turtle were $\sim 0.51 \mathrm{~m} / \mathrm{s}$ and $\sim 0.53 \mathrm{~m} / \mathrm{s}$, respectively. The turtle was constantly in motion with the lowest speed reaching $\sim 0.1 \mathrm{~m} / \mathrm{s}$. 

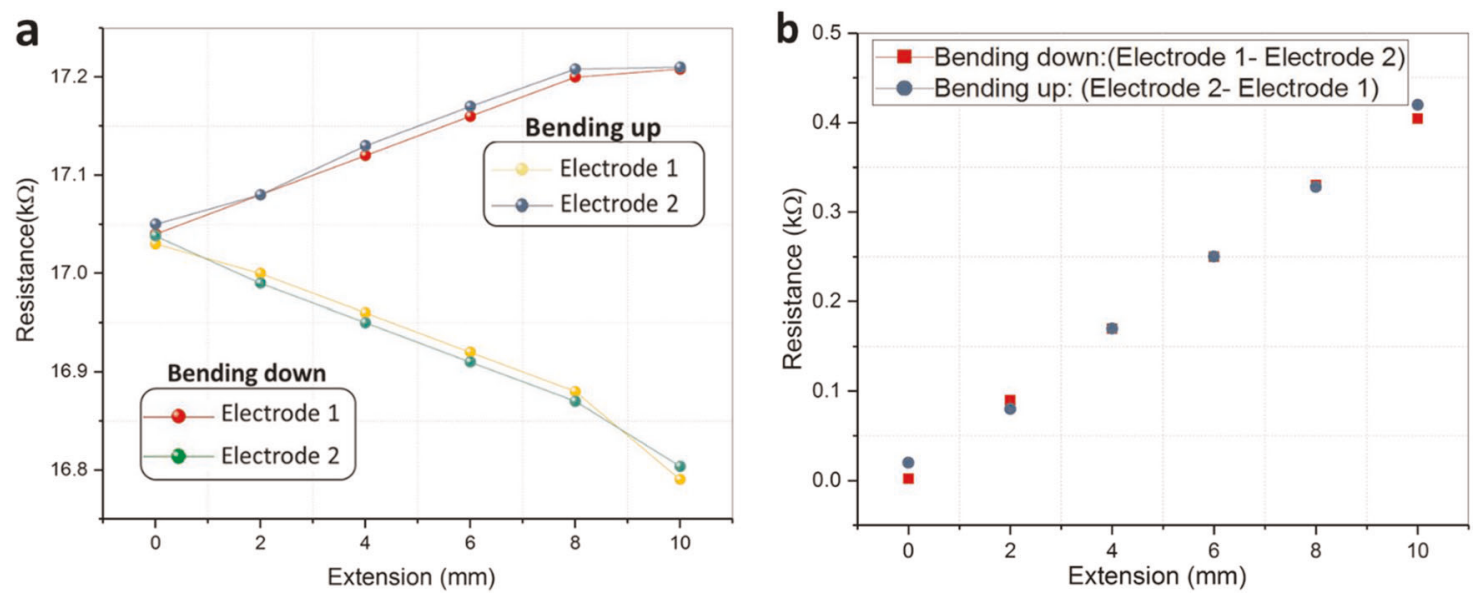

Fig. 7 a The responses of a double-sided LIG sensor to bending with the LIG under tension and compression states. $\mathbf{b}$ The results of difference measurements
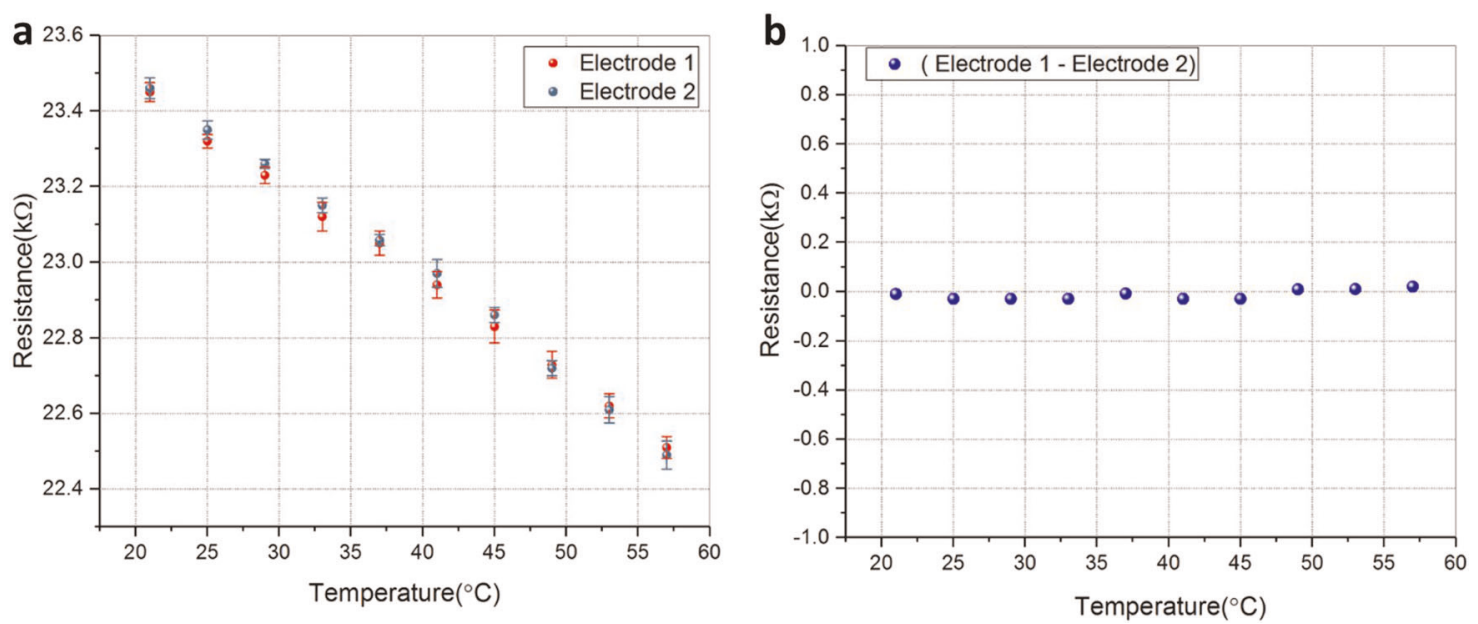

Fig. 8 a The resistance of the LIG temperature sensor as a function of temperature. Each data point represents the average of three measured values; each error bar connects the maximum and the minimum values. $\mathbf{b}$ The result of subtracting the average output signals of electrodes from each other
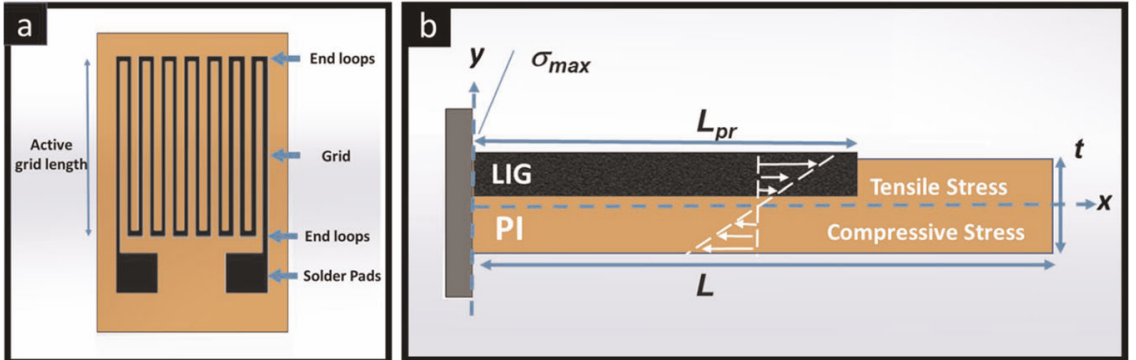

Fig. 9 a LIG electrodes (black) patterned on a flexible polyimide sheet (orange). b Schematic of a cross-section of piezoresistive cantilever beam

Flow velocity monitoring

Another LIG sensor (width: $7 \mathrm{~mm}$ length: $15 \mathrm{~mm}$, number of turns: 3) was combined with a Daily Diary tag (TDR10-DD, Wildlife computers), which had a size of $20 \times 20 \mathrm{~mm}^{2}$ (Fig. 12a), to measure the flow velocity of the underwater currents at the $\mathrm{Al}$ Fahal coral reef in the Cental Red Sea (geographic coordinates:
22.25285 ${ }^{\circ} \mathrm{N}, 38.96123{ }^{\circ} \mathrm{E}$, average salinity: $\sim 35 \%$, average temperature $\sim 33^{\circ} \mathrm{C}$ ) (Fig. 12b; Supplementary Movie 1). The result of a flow measurement over $\sim 1 \mathrm{~h}$ (Fig. 12c) reveals that surface current flow had average and median speeds of $\sim 0.47 \mathrm{~m} / \mathrm{s}$ and $\sim 0.48 \mathrm{~m} / \mathrm{s}$, respectively, with an occasional increase to a maximum speed of $\sim 0.92 \mathrm{~m} / \mathrm{s}$. The minimum speed was $\sim 0.21 \mathrm{~m} / \mathrm{s}$. 
a
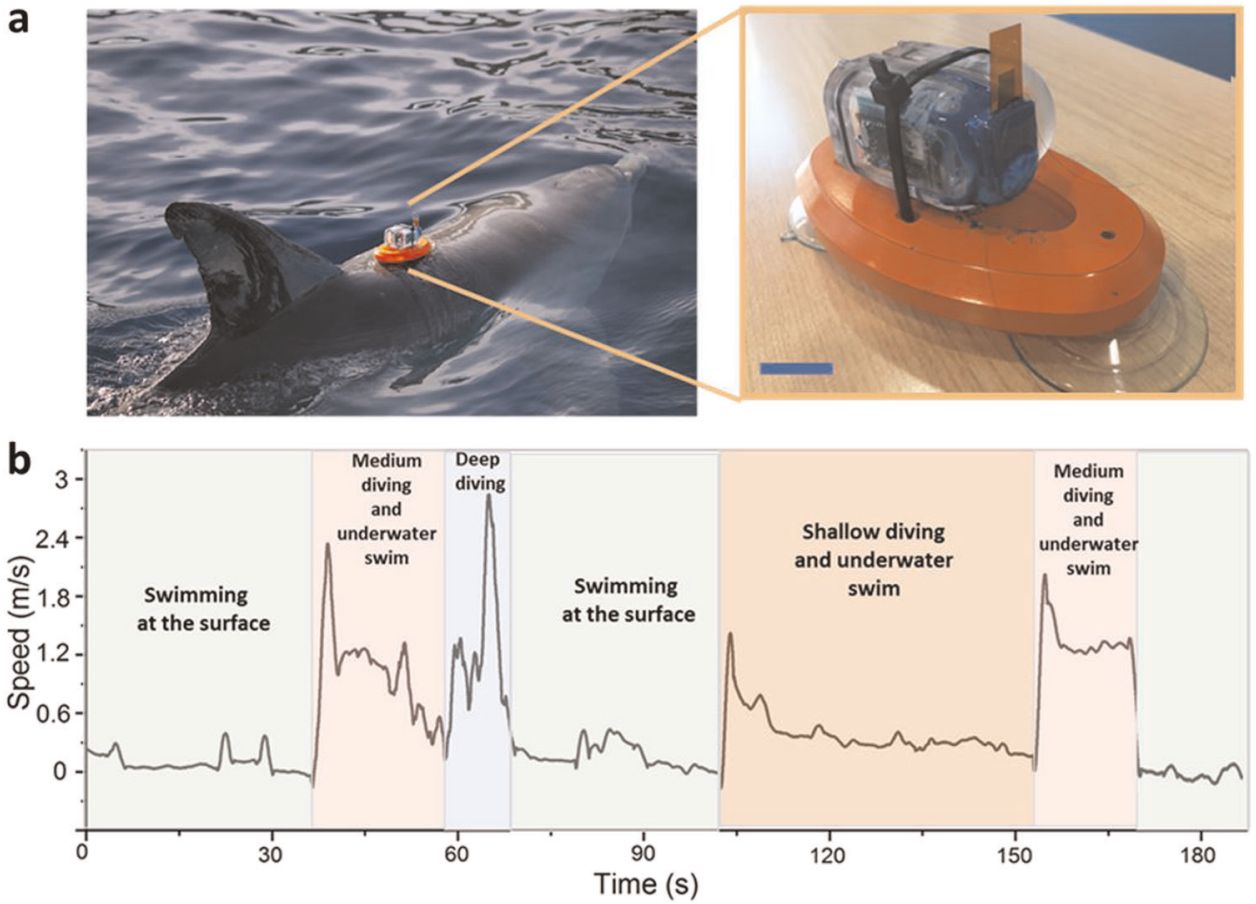

Fig. 10 a LIG bending sensor integrated with ultra-low power Aquamote tag (scale bar: $2 \mathrm{~cm}$ ) and attached to a dolphin's spine. b The resistance of the LIG sensor and corresponding swim speed of the dolphin as a function of time for a duration of 3 min

\section{a}
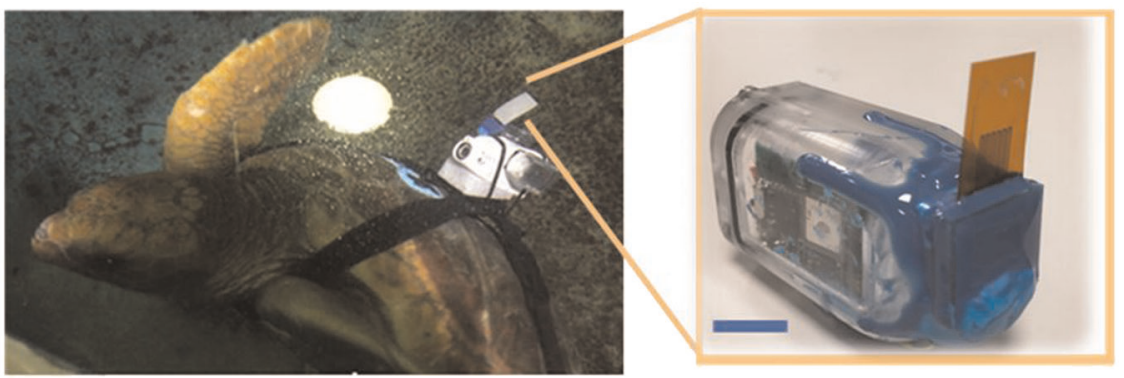

b

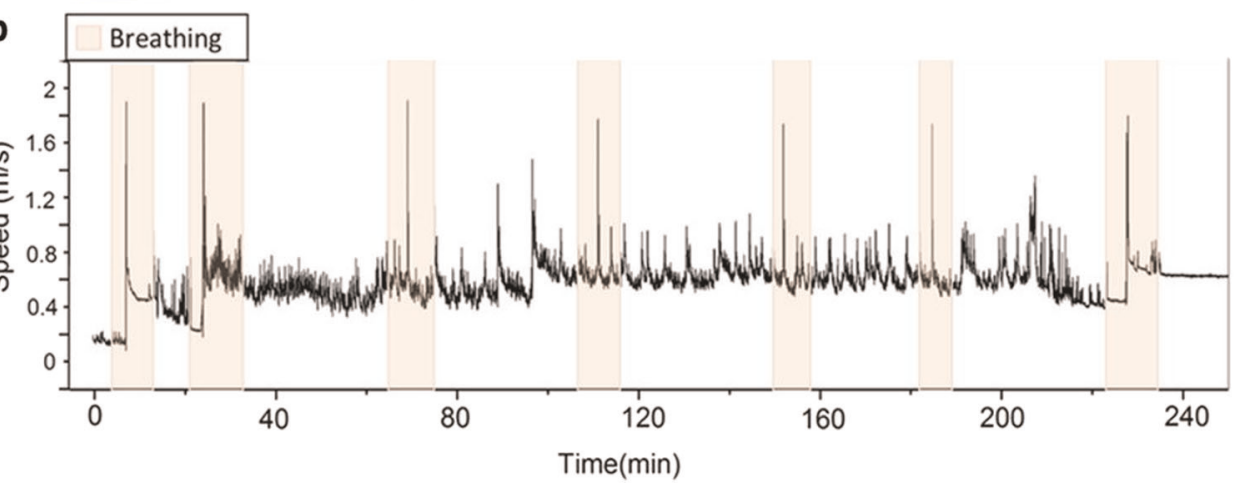

Fig. 11 a LIG bending sensor integrated with commercial tag (scale bar: $1 \mathrm{~cm}$ ) and attached to the sea turtle. $\mathbf{b}$ The recorded speed of sea turtle as a function of time for a duration of $4 \mathrm{~h}$

\section{Wearable device}

The schematic illustration of LIG bending sensors attached to various body locations for associated detection of joint-bendingrelated motions, such as fingers, elbows, knees, ankle, and neck, is shown in Fig. 13. LIG sensors of various geometry were directly and noninvasively mounted using $0.1 \mathrm{~g}$ of biocompatible petroleum jelly (Vaseline ${ }^{\circledR}$ Products). The responses of the index finger bending forward and backward consecutively with various speeds
( $\sim 0.1$ bends/min and $\sim 0.25$ bends/min) are shown Fig. 13a. Figure $13 \mathrm{~b}$ displays knee-related motions, which discriminate walking, jogging, and squatting according to their distinctly differentiated waveforms. The combinations of two or more LIG sensors would allow the measurement of multiple DOFs, such as torso, shoulder, and ankle. A hypnagogic jerk (sleep start or hypnic jerk) is a brief contraction of the body that occurs involuntarily, when a person is beginning to fall asleep, which often causes the person to jump 


\section{a}
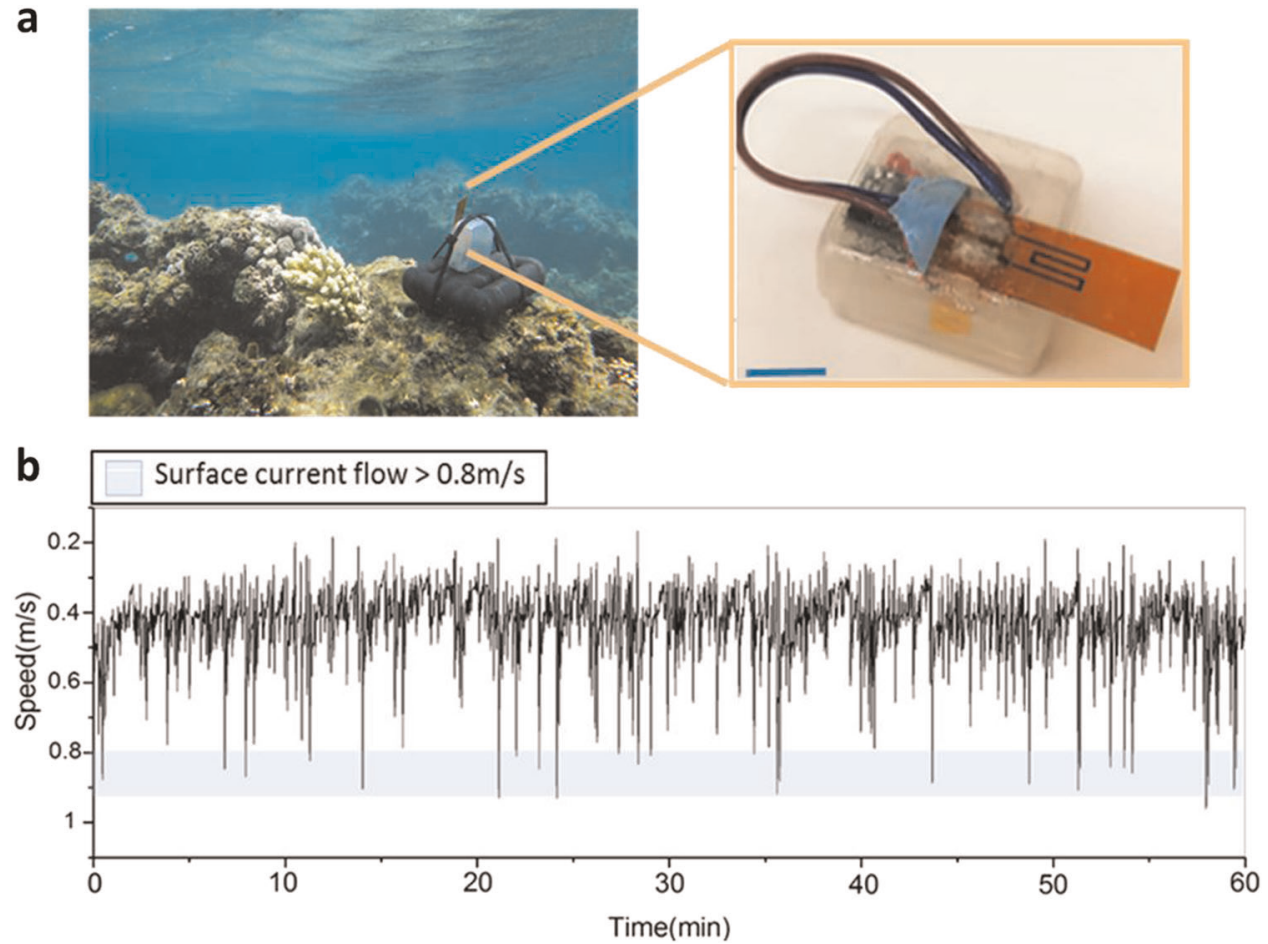

Fig. 12 a Tag deployment in Al Fahal Reef of Red sea to measure flow velocity. Inset shows the LIG bending sensor integrated with a Daily Diary tag (scale bar: $1 \mathrm{~cm}$ ). b Recorded resistance as a function of time for a duration of $1 \mathrm{~h}$
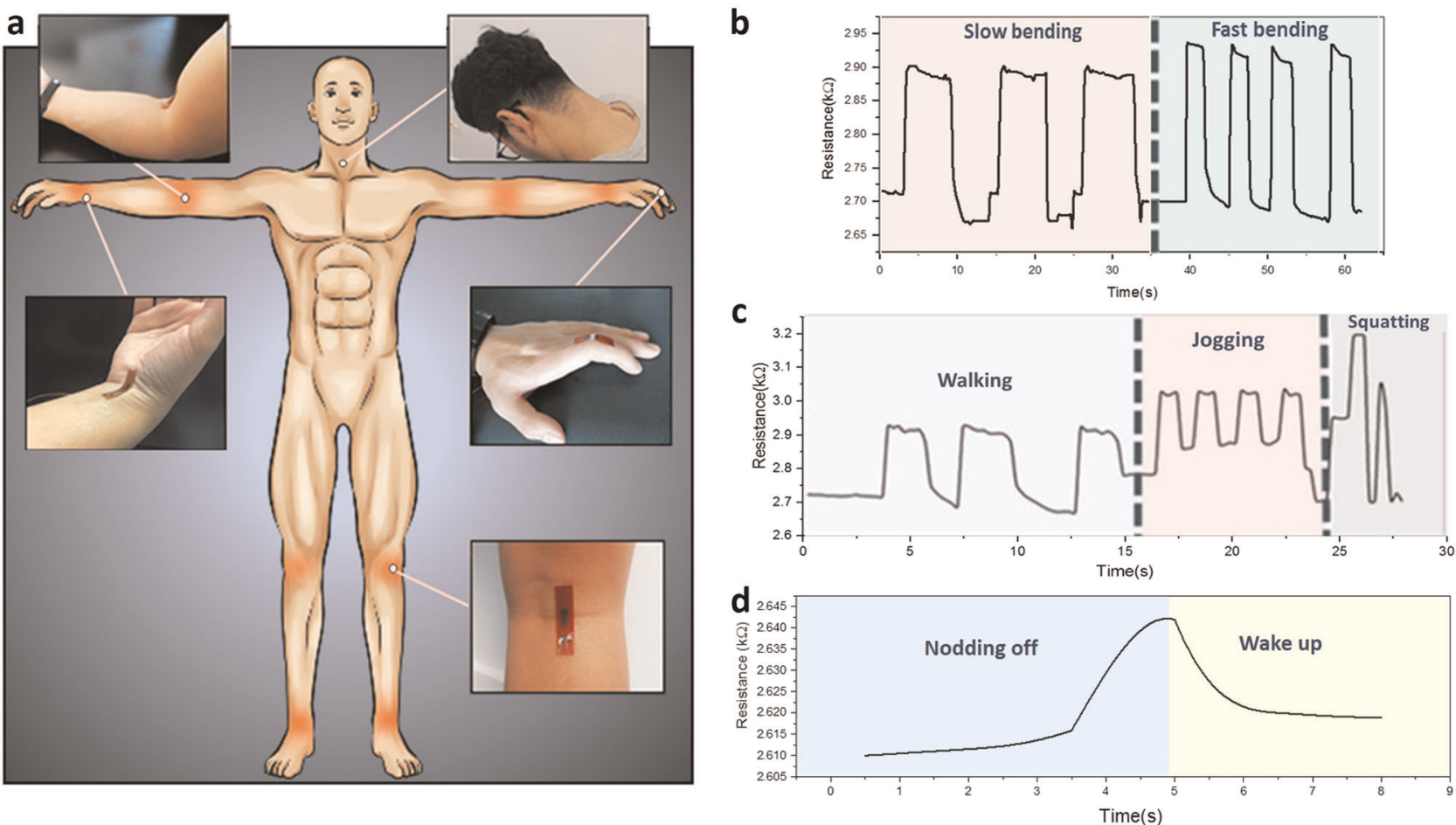

Fig. 13 a Schematic of wearable LIG bending sensors attached to different positions of a human body to monitor joint-bending-related motions. b Monitoring the response of finger bending c Knee-related motion monitoring: walking, jogging, and squatting. $\mathbf{d}$ Microsleep detection by monitoring head nodding and waking up

and awake suddenly. The associated movement of the head results in neck bending, which can be monitored for assessing drivers vigilance. ${ }^{66,67}$ This head movement was measured by means of an LIG bending sensor attached to the neck, as seen in Fig. 13c.
The outstanding material properties of LIG opened new perspectives for a versatile, durable, printed bending sensor capable of detecting flow, deflection or force across a range of conditions, and on a range of subjects. The flexibility in geometry 
and a simple fabrication process allow simple tuning of the bending sensor to achieve different sensitivities or dynamic ranges. Using tensile stress/strain measurements, a Young modulus of $2.1 \mathrm{GPa}$ and yield strength of $83 \mathrm{MPa}$ were found for the sensor with LIG printed on 125 - $\mu$ m-thick Kapton tapes. The gauge factor of LIG is 1.16 with a piezoresistive coefficient of $\sim 0.84$. The sensor has a very large range with maximum strains reaching $14 \%$. Bending tests in the form of cantilever deflection and point load showed a linear response to compressive and tensile bending of the LIG. A double-sided electrode concept was developed by printing on both sides of the Kapton. In combination with a difference measurement, an increased and homogeneous bidirectional response was obtained with full temperature compensation. The sensor can also withstand harsh environment conditions over an extended period of time.

The developed LIG sensors were applied in several applications to demonstrate their versatility, such as marine animals' speed monitoring, current flow velocity measurements in a coral reef, as well as human joint bending and motion tracking. Thereby, the LIG sensors feature lightweight and minimal intrusiveness, accommodating the requirements to monitor animals with very different velocities and behaviors. Attached to the human body, the wearable sensors operated at large bending ranges, showing a great potential for personal healthcare monitoring, smart prosthetics, and human-machine interactions.

\section{METHODS}

\section{Fabrication of LIG sensor}

Conductive porous graphene electrodes were directly patterned on commercial PI films of $125 \mu \mathrm{m}$ in thickness (Kapton \# IM301449, DuPont, Delaware, USA) using a $\mathrm{CO}_{2}$ infrared laser (wavelength $10.6 \mu \mathrm{m}$, laser spot diameter $150 \mu \mathrm{m}$, Universal Laser Systems ${ }^{\circledR}$ PLS6.75) in ambient condition and used as piezoresistors. The laser beam parameters of $3.6 \mathrm{~W}$ power, $3 \mathrm{~cm} / \mathrm{s}$ speed, 1000 pulses per inch, and $3-\mathrm{mm}$ laser-to-surface distance were tuned to obtain good adhesion of the carbon network to the substrate and achieve the porous morphology. The printed electrode pattern was structured in a meander shape (Fig. 1a) to provide a large change in resistance, while keeping the minimum electrode width ( $\sim 150 \mu \mathrm{m}$, corresponding to the laser spot diameter). To provide a stable wire connection to the sensor, $80 \mathrm{~nm}$ of gold were sputtered on top of both contact pads, as shown in Fig. 1a. The electrical wires were connected using conductive epoxy (CW2400, CircuitWorks. Inc), which features strong mechanical bonds, excellent electrical conductivity, and quick room temperature curing. Finally, in case of operation in conductive media like seawater, a polydimethylsiloxane (PDMS) coating was applied to avoid interference with the measurement, due to shunt currents. PDMS (Dow Corning Corp., Slygard ${ }^{\circledR} 184$ ) with a ratio of 10 (base):1 (curing agent) was spin coated on top (2500 revolutions per min for $90 \mathrm{~s}$ ) of the device, and the sample was placed in a vacuum desiccator for $20 \mathrm{~min}$ to eliminate air bubbles. Then, this passivation layer was cured in the oven at $80^{\circ} \mathrm{C}$ for $1 \mathrm{~h}$. The thickness of the PDMS was $10 \mu \mathrm{m}$.

\section{Working principle}

The bending sensor utilizes LIG on a flexible PI film to transduce a signal via cantilever deflection, i.e., it is supported at one end with the other end free (Fig. 1b). An external force, $F$, applied to the tip of the cantilever induces a uniaxial stress, ${ }^{68,69}$

$\sigma=\frac{F(L-d) c}{I_{A}}$

where, $L$ is the cantilever length, $c$ is the distance to the neutral axis, $d$ is the distance from the support, and $I_{A}$ is the area moment of inertia. Therefore, the longitudinal stress varies linearly through the cantilever thickness and along its length. The maximum stress, $\sigma_{\max }$ occurs at the surface of the cantilever at the anchor point, as shown in Fig. 1b. The interaction of sensor with an external force, such as water flow, along the $y$-axis induces a cantilever bending and fractional resistance change that can be approximated by ${ }^{68-71}$

$\frac{\Delta R}{R}=\pi_{1} \sigma_{\max }=\frac{6 \pi_{1}\left(L-L_{\mathrm{pr}} / 2\right)}{w t^{2}} F$,

where $\pi_{1}$ is the piezoresistive coefficient, $L_{p r}$ is the length of the piezoresistor, $\mathrm{t}$ and $w$ are the thickness and width of the cantilever, respectively. Hence, the sensitivity of the sensor is tuned by the length and cross-sectional area of the sensor substrate and the length of the piezoresistor.

All studies, and the current study, were performed under approvals Oce4-18 and Oce-12-18- by the Animal Care and Use Committee at the Oceanogràtic. In addition, all studies at the Oceanogràfic were supervised by veterinary and husbandry at staff of the Oceanografic. All procedures involving human were approved by the KAUST Institutional Biosafety and Bioethics Committee (IBEC). The volunteers provided signed consent to participate in the study.

\section{Reporting summary}

Further information on research design is available in the Nature Research Reporting Summary linked to this article.

\section{DATA AVAILABILITY}

The data that support the findings of this study are available from the corresponding author upon reasonable request.

\section{ACKNOWLEDGEMENTS}

This research is a contribution to the CAASE project funded by King Abdullah University of Science and Technology (KAUST) under the KAUST Sensor Initiative. We thank the staff and leadership of the Oceanografic in Valencia for their help and support during the sensor tests with turtle and dolphin.

\section{AUTHOR CONTRIBUTIONS}

The research aims and methods were proposed by A.K. and J.K.; the fabrication process was carried out by A.K., M.A.K. and U.B; the structural characterization experiments were carried out by A.K. and M.M.; the electrical characterization experiments were handled by A.K., A.P., L.S. and C.M.; the sensors attachments to marine animals and deployment in Red sea were conducted by A.F., N.R.G. and R.P.W.

\section{ADDITIONAL INFORMATION}

Supplementary information accompanies the paper on the npj Flexible Electronics website (https://doi.org/10.1038/s41528-019-0061-5).

Competing interests: The authors declare no competing interests.

Publisher's note: Springer Nature remains neutral with regard to jurisdictional claims in published maps and institutional affiliations.

\section{REFERENCES}

1. Syed, A., Agasbal, Z. T., Melligeri, T. \& Gudur, B. Flex sensor based robotic arm controller using micro controller. J. Softw. Eng. Appl. 5, 364 (2012).

2. Saggio, G., Riillo, F., Sbernini, L. \& Quitadamo, L. R. Resistive flex sensors: a survey. Smart Mater. Struct. 25, 013001 (2015).

3. Zhou, H. \& Hu, H. Human motion tracking for rehabilitation-a survey. Biomed. Signal Process. Control 3, 1-8 (2008).

4. Kaniusas, E. et al. Method for continuous non-disturbing monitoring of blood pressure by magnetoelastic skin curvature sensor and ECG. IEEE Sens. J. 6, 819-828 (2006).

5. Giouroudi, I. et al. Magnetostrictive bilayer sensor for micro-torque measurements. Sens. Lett. 5, 304-307 (2007).

6. Levangie, P. K. \& Cynthia, N. C. Joint Structure and function: A Comprehensive Analysis, 3rd edn. (FA. Davis Company, Philadelphia, 2000).

7. Jepsen, N., Thorstad, E. B., Havn, T. \& Lucas, M. C. The use of external electronic tags on fish: an evaluation of tag retention and tagging effects. Anim. Biotelemetry 3, 49 (2015).

8. Wang, P. T., King, C. E., Do, A. H. \& Nenadic, Z. A durable, low-cost electrogoniometer for dynamic measurement of joint trajectories. Med. Eng. Phys. 33, 546-552 (2011). 
9. Kumar, P., Rautaray, S. S. \& Agrawal, A. Hand data glove: a new generation realtime mouse for human-computer interaction. In Recent Advances in Information Technology (RAIT), 2012 1st Int. Conf. on: IEEE, 750-755 (2012).

10. Cochrane, C., Koncar, V., Lewandowski, M. \& Dufour, C. Design and development of a flexible strain sensor for textile structures based on a conductive polymer composite. Sensors 7, 473-492 (2007).

11. Jurgens, J. \& Patterson, P. E. Development and evaluation of an inexpensive sensor system for use in measuring relative finger positions. Med. Eng. Phys. 19, 1-6 (1997).

12. Shyr, T. W., Shie, J. W., Jiang, C. H. \& Li, J. J. A textile-based wearable sensing device designed for monitoring the flexion angle of elbow and knee movements. Sensors 14, 4050 (2014).

13. Gibbs, P. \& Asada, H. H. Wearable conductive fiber sensors for measuring joint movements. InRobotics Autom. 5, 4753-4758 (2004).

14. Bessonov, A., Kirikova, M., Haque, M., Gartseev, S. \& Bailey, I. MJ, Highly reproducible printable graphite strain gauges for flexible devices. Sens. Actuators A: Phys. 206, 75-80 (2014).

15. Skotadis, E., Mousadakos, D., Katsabrokou, K., Stathopoulos, S. \& Tsoukalas, D. Flexible polyimide chemical sensors using platinum nanoparticles. Sens. Actuators B: Chem. 189, 106-112 (2013).

16. Biddiss, E. \& Chau, T. Electroactive polymeric sensors in hand prostheses: bending response of an ionic polymer metal composite. Med. Eng. Phys. 28, 568-578 (2006).

17. Neto, A. C., Guinea, F., Peres, N. M., Novoselov, K. S. \& Geim, A. K. The electronic properties of graphene. Rev. Mod. Phys. 81, 109 (2009).

18. Zhao, X., Zhang, Q., Chen, D. \& Lu, P. Enhanced mechanical properties of graphene-based poly (vinyl alcohol) composites. Macromolecules 43, 2357-2363 (2010).

19. Yokaribas, V. et al. Strain gauges based on CVD graphene layers and exfoliated graphene nanoplatelets with enhanced reproducibility and scalability for large quantities. Sensors 17, 2937 (2017).

20. Hosseinzadeh, A., Bidmeshkipour, S., Abdi, Y., Arzi, E. \& Mohajerzadeh, S. Graphene based strain sensors: a comparative study on graphene and its derivatives. Appl. Surf. Sci. 448, 71-77 (2018).

21. Kim, K. S. et al. Large-scale pattern growth of graphene films for stretchable transparent electrodes. Nature 457, 706-710 (2009).

22. Young, R. J. et al. Strain mapping in a graphene monolayer nanocomposite. Acs Nano 5, 3079-3084 (2011).

23. Raju, A. P. A. et al. Wide-area strain sensors based upon graphene-polymer composite coatings probed by Raman spectroscopy. Adv. Funct. Mater. 24, 2865-2874 (2014)

24. Wang, Y. et al. Flexible electrically resistive-type strain sensors based on reduced graphene oxide-decorated electrospun polymer fibrous mats for human motion monitoring. Carbon 126, 360-371 (2018).

25. $\mathrm{Hu}, \mathrm{C}$. et al. Comparative assessment of the strain-sensing behaviors of polylactic acid nanocomposites: reduced graphene oxide or carbon nanotubes. J. Mater Chem. C. 5, 2318-2328 (2018).

26. Xu, M., Qi, J., Li, F. \& Zhang, Y. Highly stretchable strain sensors with reduced graphene oxide sensing liquids for wearable electronics. Nanoscale 10, 5264-5271 (2018).

27. Park, J. J. et al. Highly stretchable and wearable graphene strain sensors with controllable sensitivity for human motion monitoring. ACS Appl. Mater. Interfaces 7, 6317-6324 (2015)

28. Frank, O. et al. Compression behavior of single-layer graphenes. ACS Nano 4 3131-3138 (2015). 2010

29. Ni, Z. H. et al. Uniaxial strain on graphene: Raman spectroscopy study and bandgap opening. ACS Nano 2, 2301-2305 (2008).

30. Gong, L. et al. Interfacial stress transfer in a graphene monolayer nanocomposite. Adv. Mater. 22, 2694-2697 (2010)

31. Eswaraiah, V., Balasubramaniam, K. \& Ramaprabhu, S. One-pot synthesis of conducting graphene-polymer composites and their strain sensing application. Nanoscale 4, 1258-1262 (2012).

32. Lin, J. et al. Laser-induced porous graphene films from commercial polymers. Nat Commun. 5, 5714 (2014).

33. Kaidarova, A. et al. Flexible and biofouling independent salinity sensor. Adv. Mater. Interfaces 5, 1801110 (2018).

34. Ye, R., James, D. K. \& Tour, J. M. Laser-induced graphene: from discovery to translation. Adv. Mater. 31, 1803621 (2019).

35. Luo, S., Hoang, P. T. \& Liu, T. Direct laser writing for creating porous graphitic structures and their use for flexible and highly sensitive sensor and sensor arrays. Carbon 96, 522-531 (2016)

36. Naveed, S., Malik, T., Muneer, M. \& Ali Mohammad, M. A laser scribed graphene oxide and polyimide hybrid strain sensor. Key Eng. Mater. 778, 169-174 (2018).

37. Strong, V. Patterning and electronic tuning of laser scribed graphene for flexible all-carbon devices. ACS Nano 6, 1395-1403 (2012).
38. Rahimi, R., Ochoa, M., Yu, W. \& Ziaie, B. Highly stretchable and sensitive unidirectional strain sensor via laser carbonization. ACS Appl. Mater. Interfaces 7 4463-4470 (2015).

39. Zhang, C. et al. Reversible self-assembly of 3D architectures actuated by responsive polymers. ACS Appl. Mater. Interfaces 9, 41505-41511 (2017).

40. $\mathrm{Wu}, \mathrm{Y}$. et al. Piezoresistive stretchable strain sensors with human machine interface demonstrations. Sens. Actuators A: Phys. 279, 46-52 (2018).

41. Luong, D. X. et al. Laser-induced graphene composites as multifunctional surfaces. ACS Nano. 13, 2579-2586 (2019).

42. Carvalho, A. F. et al. Laser-induced graphene strain sensors produced by ultraviolet irradiation of polyimide. Adv. Funct. Mater. 28, 1805271 (2018).

43. Tao, L. Q. et al. An intelligent artificial throat with sound-sensing ability based on laser induced graphene. Nat. Commun. 8, 14579 (2017).

44. Tao, L. Q. et al. Self-adapted and tunable graphene strain sensors for detecting both subtle and large human motions. Nanoscale 9, 8266-8273 (2017).

45. Chaidez, V., Dreano, D., Agusti, S., Duarte, C. M. \& Hoteit, I. Decadal trends in Red Sea maximum surface temperature. Sci. Rep. 7, 8144 (2017).

46. Rasul, N. M. \& Stewart, I. C. The Red Sea: The Formation, Morphology, Oceanography and Environment of a Young Ocean Basin (Springer, Verlag, Berlin, 2015).

47. Bograd, S. J., Block, B. A., Costa, D. P. \& Godley, B. J. Biologging technologies: new tools for conservation. Introd., Endanger. Species Res. 10, 1-7 (2010).

48. Gleiss, A. C., Wilson, R. P. \& Shepard, E. L. Making overall dynamic body acceleration work: on the theory of acceleration as a proxy for energy expenditure. Methods Ecol. Evol. 2, 23-33 (2011).

49. Ponganis, P. J. et al. Swimming velocities in otariids. Can. J. Zool. 68, 2105-2112 (1990).

50. Sato K. et al. Stroke frequency, but not swimming speed, is related to body size in free-ranging seabirds, pinnipeds and cetaceans. Proc. Roy. Soc. London B: Biol. Sci. 274, 471-477 (2007)

51. Wilson, R. P. et al. Diel dive depth in penguins in relation to diel vertical migration of prey: whose dinner by candlelight? Mar. Ecol. Prog. Ser. 94, 101-114 (1993).

52. Shepard, E. L. et al. Flexible paddle sheds new light on speed: a novel method for the remote measurement of swim speed in aquatic animals, Endangered Species. Research 4, 157-164 (2008).

53. Mulligan, A. E., Gardner, A. T., Hammar, T., Harvey, C. \& Hemond, H. F. inventors; Woods Hole Oceanographic Institute (WHOI), assignee, Differential pressure systems and methods for measuring hydraulic parameters across surface wateraquifer interfaces. US Pat. US8 825, 430 (2014). Sep 2.

54. Tardi, G., Massaroni, C., Saccomandi, P. \& Schena, E. Experimental assessment of a variable orifice flowmeter for respiratory monitoring. J. Sensors 752540, 1-7 (2015).

55. Han, Y., Jin, N., He, Y. \& Ren, Y. Flow measurement of oil-in-water emulsions using arc-type conductivity probes and electromagnetic flowmeter. IEEE Trans. Instrum. Meas. 67, 667-677 (2018)

56. Zheng, D., Zhang, T. \& Hu, Y. Experimental investigations of the location of piezoelectric probe in a vortex flow sensor. Meas. Sci. Technol. 18, 3777 (2007).

57. Fuchs, S. I. et al. Multiple breath washout with a sidestream ultrasonic flow sensor and mass spectrometry: a comparative study. Pediatr. Pulmonol. 41, 1218-1225 (2006).

58. Haneveld, J. et al. Modeling, design, fabrication and characterization of a micro Coriolis mass flow sensor. J. Micromech. Microeng. 20, 125001 (2010).

59. Kuila, T. et al. Chemical functionalization of graphene and its applications. Prog. Mater. Sci. 57, 1061-1105 (2012).

60. Cançado, L. G. et al. Quantifying defects in graphene via Raman spectroscopy at different excitation energies. Nano Lett. 11.8, 3190-3196 (2011).

61. Ferrari, A. C. et al. Raman spectrum of graphene and graphene layers. Phys. Rev. Lett. 97, 187401 (2006)

62. Bauer, C. L. \& Farris, R. J. Determination of poisson's ratio for polyimide films. Polym. Eng. Sci. 29, 1107-1110 (1989).

63. Marengo, M., Marinaro, G. \& Kosel, J. Flexible temperature and flow sensor from laser-induced graphene. InSENSORS 2017, 1-3 (2017). IEEE.

64. Lee, E. S., Jeyakumar, J. V., Balaji, B., Wilson, R. P. \& Srivastava, M. AquaMote: ultra low power sensor tag for animal localization and fine motion tracking. in Proceedings of the 15th ACM Conference on Embedded Network Sensor Systems, (ed. Eskicioglu, R.) Vol. 71 (ACM, New York, NY, USA, 2017).

65. Wilson RP, R. P., Shepard, E. L. \& Liebsch, N. Prying into the intimate details of animal lives: use of a daily diary on animals. Endanger. Species Res. 4, 123-137 (2008)

66. Zadra, A., Desautels, A., Petit, D. \& Montplaisir, J. Somnambulism: clinical aspects and pathophysiological hypotheses. Lancet Neurol. 12, 285-294 (2013).

67. Mukhopadhyay, S. C. Wearable sensors for human activity monitoring: a review. IEEE Sens. J. 15, 1321-1330 (2015).

68. Doll, J. C., Park, S. J. \& Pruitt, B. L. Design optimization of piezoresistive cantilevers for force sensing in air and water. J. Appl. Phys. 106, 064310 (2009).

69. Harkey, J. A. \& Kenny, T. W. 1/f noise considerations for the design and process optimization of piezoresistive cantilevers. J. Micro. Syst. 9, 226-235 (2000). 
70. Doll, J. C. et al. Piezoresistive cantilever optimization and applications. MRS Online Proceedings Library Archive, 1222 (2009).

71. Park S. J. et al. Optimization of piezoresistive cantilever performance. Hilton Head Sensors, Actuators and Microsystems Workshop. In Proceedings of the Solid-State Sensors and Actuators Workshop, Vol. 3 (Digest Tech, Hilton Head Island, SC, 2008).

Open Access This article is licensed under a Creative Commons cc) Attribution 4.0 International License, which permits use, sharing, appropriate credit to the original author(s) and the source, provide a link to the Creative
Commons license, and indicate if changes were made. The images or other third party material in this article are included in the article's Creative Commons license, unless indicated otherwise in a credit line to the material. If material is not included in the article's Creative Commons license and your intended use is not permitted by statutory regulation or exceeds the permitted use, you will need to obtain permission directly from the copyright holder. To view a copy of this license, visit http://creativecommons. org/licenses/by/4.0/.

(c) The Author(s) 2019 